\title{
Morphological and functional characterizations of Schwann cells stimulated with Mycobacterium leprae
}

\author{
Tatiana Pereira da Silva, Ana Caroline Costa da Silva, Maria da Graça Araújo Baruque, \\ Rosane Barbosa de Oliveira, Marcelo Pelajo Machado', Euzenir Nunes Sarno/ ${ }^{+}$
}

Laboratório de Hanseníase 'Laboratório de Patologia, Instituto Oswaldo Cruz-Fiocruz, Av. Brasil 4365, 21045-900 Rio de Janeiro, RJ, Brasil

Nerve damage, a characteristic of leprosy, is the cause of patient deformities and a consequence of Schwann cells (SC) infection by Mycobacterium leprae. Although function/dysfunction of SC in human diseases like leprosy is difficult to study, many in vitro models, including SC lines derived from rat and/or human Schwannomas, have been employed. ST88-14 is one of the cell lineages used by many researchers as a model for M. leprae/SC interaction. However, it is necessary to establish the values and limitations of the generated data on the effects of $\mathrm{M}$. leprae in these SC. After evaluating the cell line phenotype in the present study, it is close to non-myelinating SC, making this lineage an ideal model for $\mathrm{M}$. leprae/SC interaction. It was also observed that both $\mathrm{M}$. leprae and PGL-1, a mycobacterial cell-wall component, induced low levels of apoptosis in ST88-14 by a mechanism independent of Bcl-2 family members.

Key words: Schwann cell - Mycobacterium leprae - apoptosis

The function/dysfunction of Schwann cells (SC) in human disease is difficult to study. In an attempt to bypass some of these difficulties, tissues obtained during different phases of experimental and naturally occurring peripheral neural system diseases in animals or those employed using in vitro models can efficiently serve as a basis for study. The latter include dissociated primary human and animal SC as well as SC lines derived from rat and/or human Schwannomas (Yan et al. 1995).

Both in vivo and in situ approaches, however, have inherent limitations. SC/nervous system interdependence leads to mutual disturbances. For example, experimental and genetically determined SC diseases often result in axonal pathology (Ryan et al. 1994). Mycobacterium leprae, the causative agent of leprosy, presents a unique characteristic among human pathogens in its ability to invade and survive inside SC (Rambukkana et al. 1997). Although the pathogenesis of leprosy neuropathy is far from being fully understood, this event is the basis of the sensory and motor loss leading to the disabilities and deformities commonly associated with this disease (Agrawal et al. 2005).

The non-myelinating SC is the target of $M$. leprae entry and survival in escaping from the bactericidal activity of macrophages. M. leprae is easily seen inside vacuoles in the non-myelinating SC cytoplasm in nerve specimens of leprosy patients, but the direct effects of this have yet to be clarified (Aung et al. 2007). It has been proposed that the cell wall of pathogenic mycobac-

Financial support: Faperj, CNPq

+ Corresponding author: euzenir@fiocruz.br

Received: 21 February 2008

Accepted 20 June 2008 teria contains most of the elements associated with disease pathogenesis. Recent data have shown that, in order to adhere and activate SC, M. leprae and its glycolipid component PGL-I utilize molecules on the basal lamina and membrane of SC (e.g., laminin $\alpha 2$ and the neuregulin receptor Erb2, respectively). These events result in demyelination in rat SC co-cultures (Vincent et al. 2000, Tapinos \& Rambukkana 2005).

SC change their phenotype during development and after nerve injury. These phenotypes are capable of undergoing dedifferentiation, transdifferentiation, and apoptosis depending on the stimulus (Barry \& Beaman 2006). These changes are orchestrated by a range of neurons and cytokines secreted into the damaged environment and SC autocrine factors. In adult life, myelinating and non-myelinating SC share some common markers but also exhibit molecules that identify each of the mature SC (Bhatheja \& Field 2006, Mirsky \& Jessen 2007). Malignant Schwannoma occur frequently in neurofibromatosis type 1 (NF-1, von Recklinghausen's diseases) in conjunction with germ line alterations in the NF-1 gene at 17q11.2 (Yan et al. 1995).

ST88-14 was one SC line among these Schwannomas immortalized by Yan et al. (1995). Over the last decade, it has been used by researchers as a model for M. leprael SC interaction. (Im et al. 2006). The resulting studies have shown that $M$. leprae can invade SC (Marques et al. $2001 b$ ) by a specific laminin-binding protein of $21 \mathrm{kDa}$ (Marques et al. 2001a) in addition to PGL-I (Ng et al. 2000). Furthermore, Oliveira et al. (2003) have demonstrated the expression of Toll-like receptors within ST88-14 that can be activated by M. leprae lipoproteins and, consequently, lead to apoptosis and cytokine release by SC. More recently, the mannose receptor, which facilitates M. leprae entry into SC in this cell line, has been identified (Cruz 2006). Although ST88-14 has been characterized as an SC cell lineage and used as a model 
of $M$. leprae/SC interaction, a better characterization of the range of its biological and pathological responses to $M$. leprae infection is still needed to establish the value and limitations of the effects of M. leprae in these cells.

Data from the present study suggested that the ST8814 phenotype is close to non-myelinating SC, thereby making it an ideal model of $M$. leprae/SC interaction. M. leprae and PGL-I also induced low levels of apoptosis in cells independent of Bcl-2 family member activation.

\section{MATERIALS AND METHODS}

Reagents - For immunohistochemistry and flow cytometry analyses (FCA), the following primary antibodies were used: rabbit anti-S100 (1:100), rabbit anti-myelin basic protein (MBP) (1:50), rabbit anti-glial fibrillary acidic protein (GFAP) (1:50), mouse anti-ninjurin (1:50), rabbit anti-laminin (1:100), and mouse anti-CD44 (1:50) polyclonal antibodies (DakoCytomation, Denmark). The secondary antibodies used were goat anti-mouse fluorescein isothiocyanate (FITC) conjugate affinitypurified IgG1 and goat anti-rabbit FITC-conjugate affinity-purified IgG (DakoCytomation, Denmark). Respective IgGs (mouse IgG1 and rabbit IgG) were adopted as negative controls.

Irradiated armadillo-derived M. leprae was provided by Dr. Brennan (Department of Microbiology, Colorado State University, Fort Collins, USA). Freeze-dried AraLAM from rapid-growing Mycobacterium smegmatis and ManLAM from Mycobacterium tuberculosis strain H37Rv were provided by Dr. John T. Belisle (CST, Fort Collins, USA). They were reconstituted in RPMI $(1 \mathrm{mg} / \mathrm{ml})$ and stored at $4^{\circ} \mathrm{C}$. PGL-I was provided by John S. Spencer (CST, Fort Collins, USA) and reconstituted in PBS $\left(1 \mathrm{mg} / \mathrm{ml}\right.$, stored at $\left.4^{\circ} \mathrm{C}\right)$. The purification of PGL-1 has been previously described by Ng et al. (2000). The concentration of PGL-I used in this study was based on a dose-response curve performed by $\mathrm{Ng}$ et al. (2000). All reagents used in the in vitro cultures were shown to contain less than $0.1 \mathrm{U} / \mathrm{ml}$ endotoxin as measured by the Limulus amebocyte lysate assay (Whittaker Bioproducts, Walkersville, USA).

SC line culture - The ST88-14 tumor cell line, established from malignant Schwannomas (neurofibrosarcoma) of patients with NF-1 (Oliveira et al. 2003), was generously donated by J. A. Fletchter (Dana Farber Cancer Institute, Boston, USA). Cells were grown in RPMI 1640 medium supplemented with $100 \mathrm{U}$ of penicillin $/ \mathrm{ml}$, $100 \mu \mathrm{g}$ of streptomycin $/ \mathrm{ml}, 2 \mathrm{mM}$ L-glutamine, and $15 \%$ fetal calf serum (FCS, HyClone, Logan, USA) in a humidified $\mathrm{CO}_{2}$ incubator at $37^{\circ} \mathrm{C}$. For in vitro assays, the attached ST88-14 cells were released with trypsin/ $\operatorname{EDTA}(0.25 \% / 1 \mathrm{mM})$ for $1 \mathrm{~min}$, washed, and suspended in culture medium for culturing $7 \times 10^{4}$ cells/well in 24 well plates (Falcon, Franklin Lakes, USA) for in vitro stimulations.

For morphological evaluation, control cells were seeded on glass coverslips for $24 \mathrm{~h}$ incubation. The cells were removed and immunolabeled. For FCA, SC were cultured onto 24 -well plates for $24 \mathrm{~h}$ at $37^{\circ} \mathrm{C}$ either in the presence or absence of one of the following stimuli: M. leprae at a multiplicity of infection (MOI) of 50:1 or PGL-I, ManLAM and AraLAM at a final concentration of $10 \mu \mathrm{g} / \mathrm{ml}$. For gene expression analysis, cells were cultured in 6-well plates in the presence or absence of stimulus for $3 \mathrm{~h}$ and $6 \mathrm{~h}$ at $37^{\circ} \mathrm{C}$.

Immunolabeling - SC were cultured in 24-well plates containing glass coverslips covered with $4 \%$ silane (Sigma Chemical Company; St. Louis, USA). The samples were washed with PBS and fixed in 1\% paraformaldehyde for staining with anti-MBP, anti-GFAP, anti-Laminin, and anti-ninjurin or with methanol for anti-S100 and CD44. The samples were blocked and permeabilized in $0.5 \%$ Triton $\mathrm{X}-100 / 10 \%$ goat serum $/ 10 \%$ FCS in PBS (anti-MBP, anti-GFAP, anti-laminin, and anti-CD44). Alternatively, they were permeabilized in $0.05 \%$ NP40 and blocked in $10 \%$ AB Human serum in PBS (antiS100, anti-ninjurin). They were subsequently incubated with primary antibodies (anti-MBP, anti-GFAP, and anti-S100). Secondary antibodies (fluorescein isothiocyanate-goat anti-rabbit IgG) were added and incubated for $30 \mathrm{~min}$ at room temperature (rt). Cellular DNA was stained with bisbenzimide, and coverslips were mounted with Vectashield mounting medium (Vector Laboratories). The images were obtained using LSM510 METAZEISS laser scanning microscope.

FCA - Analysis of NGF-R (nerve growth factor receptor), MBP, S100, GFAP, and Bcl 2 expression was assessed by FCA. S100 and Bcl2 intracellular staining was performed after cell fixation with 4\% PFA for $10 \mathrm{~min}$. Cells were washed in PBS and permeabilized in $0.1 \%$ saponin in PBS containing $0.1 \%$ sodium azide for $20 \mathrm{~min}$ at $4^{\circ} \mathrm{C}$. Cells marked for NGF-R, MBP, and GFAP were subsequently washed in $0.1 \%$ saponin PBS solution and incubated with rabbit primary antibodies (anti-MBP, anti-GFAP, or Bcl2) or with mouse (anti-NGF-R) for $30 \mathrm{~min}$ at $4^{\circ} \mathrm{C}$. Cells were washed again and incubated with secondary antibody (i.e., FITC conjugate goat anti-rabbit or anti-mouse) for $30 \mathrm{~min}$ at $4^{\circ} \mathrm{C}$. Cells were washed with PBS buffer and resuspended in 1\% PFA before analysis on a FACSCalibur flow cytometer. Positivity thresholds were set using irrelevant anti-rabbit IgG for MBP and GFAP or Bcl2 and anti-mouse NGF-R as negative controls. All data are expressed as median fluorescence intensity (MIF). Gating was set on large granular cells, and 10,000 gated events were collected from each sample. Data were analyzed by WinMDI 2.8 software for Windows (Joseph Trotter, Scripps Research Institute, San Diego, USA).

AnnexinV staining - AnnexinV is an anticoagulant protein that preferentially binds negatively charged phospholipids, such as phosphatidylserine, which are exposed on the outer leaflet of the cytoplasmic membrane early in the apoptotic process. Apoptotic cells were determined by staining with annexin V-FITC conjugate using the TACS ${ }^{\mathrm{TM}}$ AnnexinV-FITC apoptosis detection kit (R\&D Systems, Minneapolis, USA). Cells, at a concentration of $7 \times 10^{4} \mathrm{cells} / \mathrm{ml}$, were incubated in the presence or absence of M. leprae (MOI 50:1), PGL-I $(10 \mu \mathrm{g} / \mathrm{ml})$, ManLAM $(10 \mu \mathrm{g} / \mathrm{ml})$, or AraLAM $(10 \mu \mathrm{g} /$ $\mathrm{ml}$ ) for $24 \mathrm{~h}$ at $37^{\circ} \mathrm{C}$. Cells were then washed once with cold PBS pH 7.4 and incubated with $100 \mu$ of binding 
buffer (10 mM HEPES/ NaOH pH 7.4, $140 \mathrm{mM} \mathrm{NaCl}$, and $2.5 \mathrm{mM} \mathrm{CaCl})\left(7 \times 10^{4}\right.$ cells $\left./ \mathrm{ml}\right)$ containing $1 \mu \mathrm{l}$ of annexin V-FITC (R\&D Systems) and $10 \mu \mathrm{g} / \mathrm{ml}$ propidium iodide (PI, Sigma) in the dark for $15 \mathrm{~min} / \mathrm{rt}$; after which, $400 \mu \mathrm{l}$ of binding buffer was added. Stained cells were analyzed by FCA on a FACScalibur Flow Cytometer (Becton \& Dickinson, San Jose, USA). Data on a minimum of $10^{4}$ cells were analyzed using WinMDI 2.8 software (Joseph Trotter, San Diego, USA). Cells that stained neither with PI nor with annexinV were considered viable cells. Cells stained for annexinV were considered apoptotic cells. Cells stained only with PI were considered necrotic.

Viability and cell cycle analysis - The cell cycle distribution was determined by staining DNA with PI of Triton X-100 permeabilized cells. Briefly, 7 x $10^{4}$ cells were incubated in the presence or absence of M. leprae, PGL-I, ManLAM, or AraLAM for $24 \mathrm{~h}$. Cells were washed in 1x HBSS and incubated with PI solution $(1 \mu \mathrm{g}$ PI, $1 \mathrm{mg} / \mathrm{ml}$ RNAse and $0.02 \%$ Triton X-100) for $30 \mathrm{~min} /$ rt. The percentage of cells in the different phases of the cell cycle was measured immediately by FCA in a FACScalibur flow cytometer. Data analysis was performed by WinMDI 2.8 software for Windows. The percentage sub- $\mathrm{G}_{0} / \mathrm{G}_{1}$ peak in the hypodiploid distribution below a DNA index of one $(<2 n)$ and the percentage of proliferating cells (S phase) were calculated. Because the nucleus becomes fragmented during apoptosis and numerous individual chromatin fragments may be present in a single cell, the percentage of objects with a fractional DNA content is represented by the sub- $\mathrm{G}_{0} / \mathrm{G}_{1}$ peak (Castellino et al. 2007). For each analysis, 10,000 cells were acquired.

RNA isolation and semi-quantitative RT-PCR - For analysis of the mRNA expression, cultured SC were suspended in $1 \mathrm{ml}$ Trizol, and RNA was extracted according to the manufacturer's instructions. One microgram of total RNA was used to prepare cDNA in a reverse transcription reaction, and the samples were stored at $-20^{\circ} \mathrm{C}$ until use. Specific oligonucleotide primer pair sequences for $\beta$-actin, Bax, and Bak were used as described (Sampaio et al. 1998) and synthesized (Gibco BRL). Sequences are described in the Table. The primers were designed to avoid genomic DNA amplification. PCR in a total volume of $25 \mu \mathrm{l}$ was performed as previously detailed (Sampaio et al. 1998), and the samples amplified in a DNA thermocycler using the following program for 25 cycles ( $\beta$-actin) or 35 cycles (Bax and Bak): denaturation at $95^{\circ} \mathrm{C} / 45 \mathrm{~s}$, annealing at $60^{\circ} \mathrm{C} / 45 \mathrm{~s}$, and extension at $72^{\circ} \mathrm{C} / 90 \mathrm{~s}$. PCR products were subjected to electrophoresis on $1.7 \%$ agarose gels. Specificity of the amplified bands was validated by their predicted size ( $\beta$-actin, $267 \mathrm{bp}$; Bax, 581 bp and Bak, 528 bp). The amplified fragments were stained with ethidium bromide. For quantification, Image Master software was used. Values were normalized against the $\beta$-actin density of the same sample.

Statistical analysis - The data were analyzed by the Wilcoxon non-parametric test using SPSS 10.0 software for Windows. A p value $<0.05$ was considered to be statistically significant.

TABLE

Primer sequences used in PCR assays

\begin{tabular}{llr}
\hline $\begin{array}{l}\text { Human } \\
\text { genes }\end{array}$ & \multicolumn{1}{c}{ Primer } & $\begin{array}{r}\text { Base } \\
\text { Pair }\end{array}$ \\
\hline $\begin{array}{l}\text { b-actin F 5'CCGGCTTCGCGGGCGACGA-3' } \\
\text { b-actin R 5'CGGGAGCCACACGCAGCTCA-3' }\end{array}$ & 267 \\
Bax F & 5'GTTTCATCCAGGATCGAGCAG-3' & 581 \\
Bax R & 5'CTTCCAGATGGTGAGCGAGG-3' & \\
Bax F & 5'GCCCAGGACACAAGAGGAGGTTTC-3' 528 \\
Bax R & 5'AAACTGGCCCAACAGAACCACACC-3' & \\
\hline
\end{tabular}
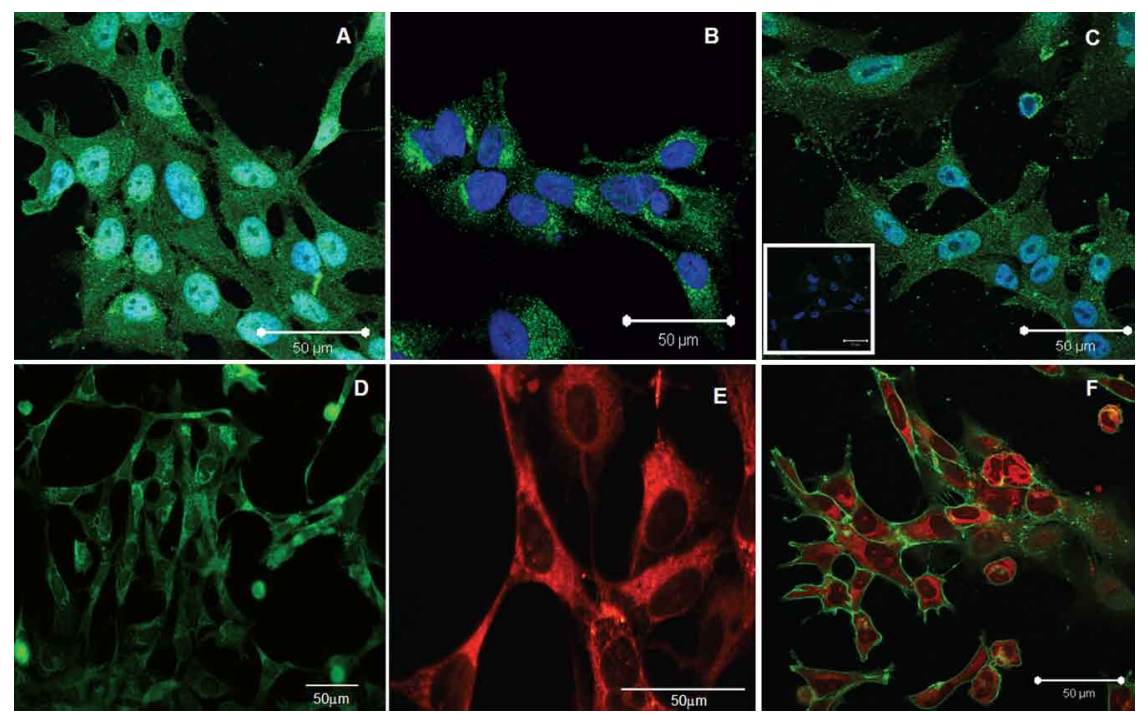

Fig. 1: immunophenotype characterization of ST88-14 line cultures. The human Schwann cell line expressed (A) S100 (green), (B) GFAP (green), (C) MBP (green) insert negative control, (D) Ninjurin (green), (E) laminin (red) and (F) CD44 (green) antibodies. Superimposed images of fluorescence bizbenzinidin blue (A, B and C) or Evans blue (F). 


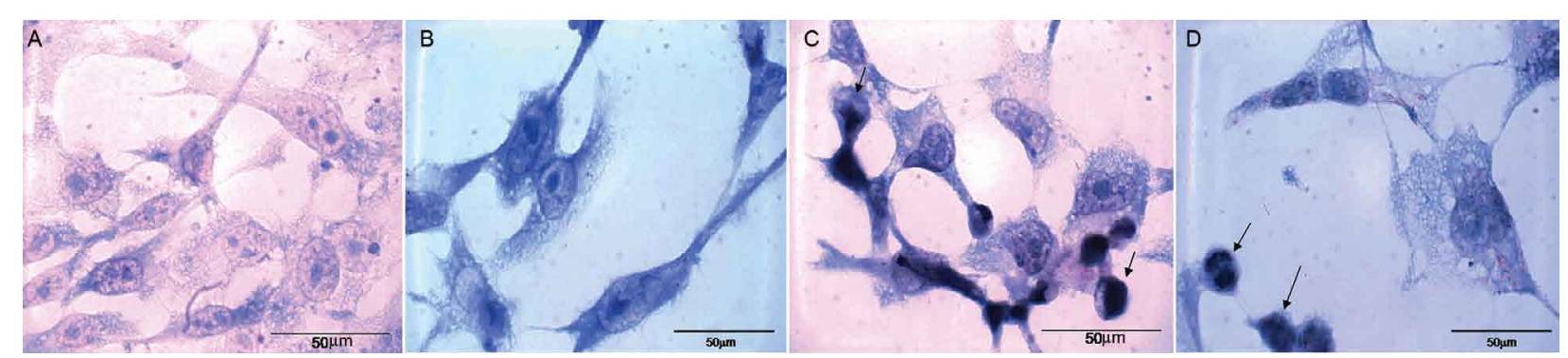

Fig. 2: Mycobacterium leprae induces apoptosis of Schwann cells (SC) in vitro. ST88-14 cultured onto glass coverslips and maintained in the absence (A, B) or presence of M. leprae for $24 \mathrm{~h}$ (C, D). SC were Ziehl-Nielsen stained (100X). Mycobacteria were found in abundance in SC cytoplasm (arrows). Apoptotic cells can by seen carrying M. leprae inside (arrow head).

A

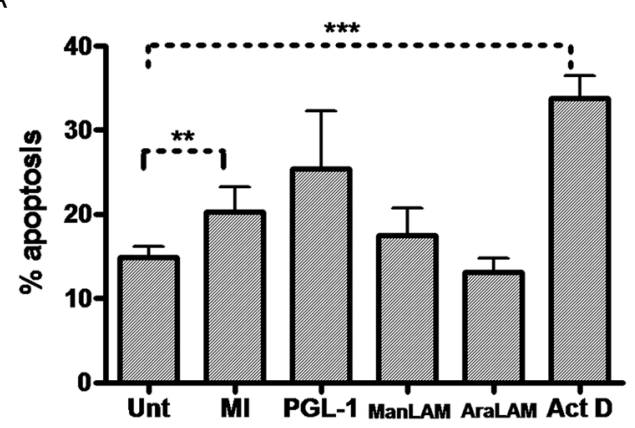

B

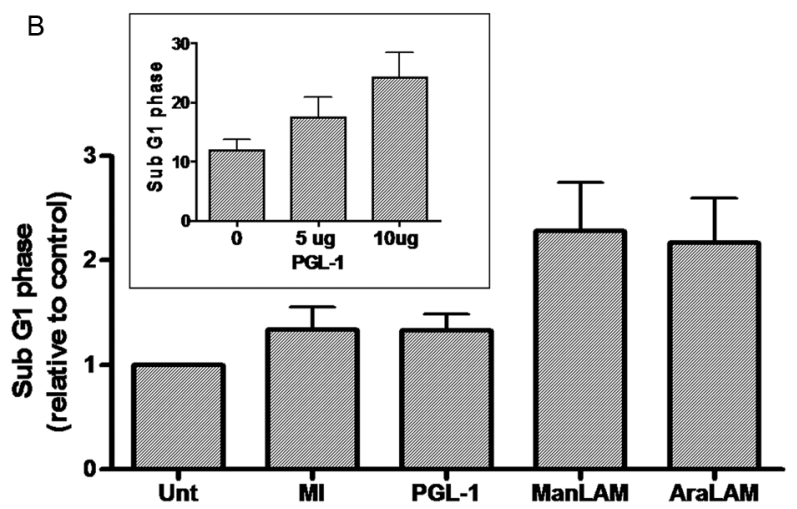

Fig. 3: effect of mycobacterial components and M. leprae on apoptosis levels in $24 \mathrm{~h} \mathrm{ST} 88-14$ cultures. Cells were incubated without (unt) and

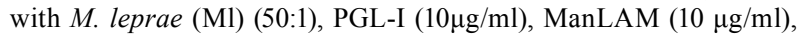
AraLAM $(10 \mu \mathrm{g} / \mathrm{ml})$, and Act D $(15 \mu \mathrm{g} / \mathrm{ml})$ for $24 \mathrm{~h}$. A: apoptosis levels assayed by AnnexinV; B: apoptosis levels by cell cycle analysis of Sub-G1 phases. Bar graph insert: the quantification of PGL-I was assessed in the culture by cell cycle analysis of Sub-G1 phases. The normalized data are shown relative to that of untreated cells. Data are the means \pm SEM from five independent experiments.

\section{RESULTS}

Phenotype markers of SC - In order to develop an in vitro model to investigate $M$. leprae/SC interactions, the SC lineage ST88-14 was characterized by immunohistochemistry and FCA. Immunostaining with S-100, CNPase (data not shown), and laminin mAbs confirmed expression of these SC markers by all cells in culture (Fig. 1A, E). The expression of the GFAP, CD44 (Fig. $1 \mathrm{~B}, \mathrm{~F}$ ) and NGF-R (data not shown) indicated that this cell line expressed important molecules that are characteristic of non-myelinating SC (Corfas et al. 2004). Even though ST88-14 cells presented a non-myelinating phenotype, a low level of MBP was detected in these cells (Fig. 1C). In addition, the ninjurin protein previously described in SC (Cardoso et al. 2007) was also detected in the ST88-14 lineage (Fig. 1D). Immunolabeling patterns varied according to the markers analyzed: S100, GFAP, MBP, Ninjurin and Laminin (Fig. 1) had a cytoplasmic distribution. CD44, a known transmembrane glycoprotein, was strongly expressed on this SC membrane (Fig. 1F). By FCA, no modulation of the S100, MBP, GFAP, or NGF-R signal was observed when $M$. leprae was added to culture (data not shown).

M. leprae effect on SC culture - The non-stimulated SC culture reaches confluence, presenting a bipolar or tripolar morphology with oval nuclei characteristic of SC (Figs 2A, B). After incubating these cells with M. leprae, the majority lost their characteristic bipolar fusiform shape and became rounded with vacuolated cytoplasm containing M. leprae. Morphological changes also occurred including an increase in cell shrinkage and nuclear condensation (Fig. 2C, D) compatible with apoptotic cells.

Effect of M. leprae and PGL-I on ST88-14 viability ST88-14 SC were incubated with $M$. leprae at a MOI of 50:1 in the presence or absence of PGL-I, ManLAM, or AraLAM at a concentration of $10 \mu \mathrm{g} / \mathrm{ml}$ in the culture medium for $24 \mathrm{~h}$. Apoptosis levels were accessed by two distinct methods: observation of phosphatidylserine externalization stained with annexinV-FITC conjugate, and hypodiploid fractionation of cells stained with PI by cellcycle analysis (Fig. 3A, B). Cells with condensed nuclei, characteristic of apoptosis, comprised $14.86 \pm 1.34 \%$ of annexinV-positive cells in the cultures in the absence of stimulus, and the frequency of apoptotic cells increased to $20.33 \pm 2.9 \%$ ( $\mathrm{p} \leq 0.05$, in relation to non-stimulated cells) in the presence of $M$. leprae and to $25.4 \pm 6.8 \%$ in the presence of the PGL-I ( $\mathrm{p} \geq 0.05)$ (Fig. 3A). Cell-cycle analysis also revealed a mild increase in DNA fragmentation by M. leprae and PGL-I stimulus (Fig. 3B). In culture stimulated with AraLAM and ManLAM, apoptosis was observed, but no significant difference was found compared to the control (Fig. 3B). These data indicate that $M$. leprae induced low levels of apoptosis and reduced cell proliferation in this human SC line. 

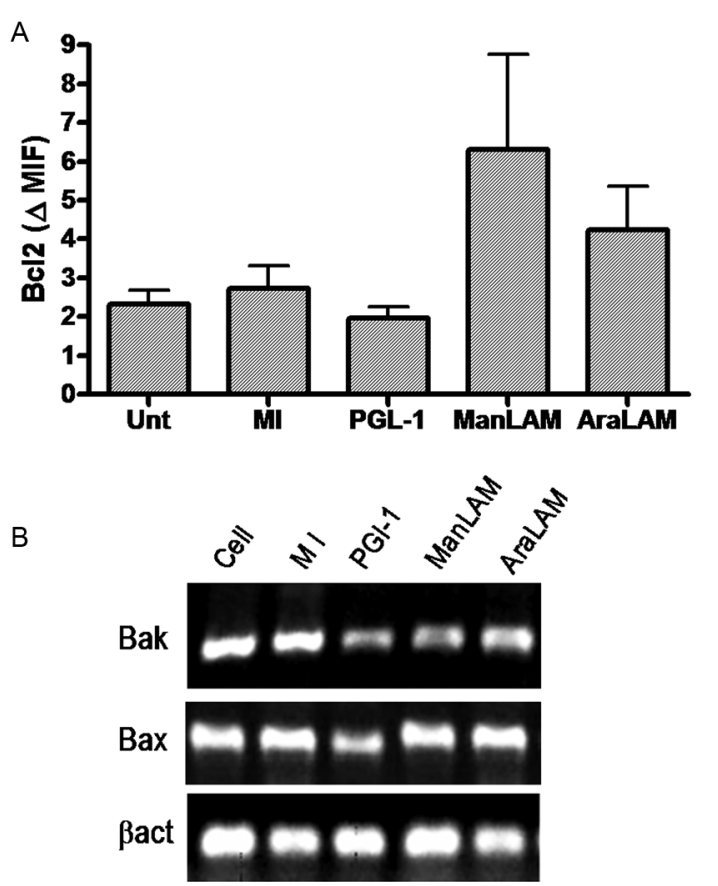

Fig. 4: Bcl-2, Bax and Bak expression in ST88-14 cell line cultures. A: cells were treated without (unt) or with M. leprae (Ml, MOI 1:50), PGL-I $(10 \mu \mathrm{g} / \mathrm{ml})$, ManLAM $(10 \mu \mathrm{g} / \mathrm{ml})$, and AraLAM $(10 \mu \mathrm{g} / \mathrm{ml})$ for $24 \mathrm{~h}$ and analyzed by flow cytometry to determine Bcl-2 protein expression. Expression of Bcl-2 was measured by the difference between mean fluorescence intensity (MIF) of stained and isotype control. Data are expressed as means \pm SEM from three independent experiments. B: RT-PCR was performed for Bax and Bak in ST88-14 cells untreated (unt) or treated with M. leprae (50:1), PGL-I (10ug/ $\mathrm{ml}$ ), ManLAM (10ug/ml), and AraLAM (10ug/ml) for $3 \mathrm{~h}$. Semiquantitative PCR for 35 cycles was performed with the appropriate primers and $\beta$-actin as a control.

Apoptosis pathway: Bcl2 family - In order to investigate the participation of Bcl2 family members in apoptosis induced by $M$. leprae on SC, mRNA expression of $B a x$ and Bak was assessed in stimulated ST88-14 culture. In addition, the expression of the $\mathrm{Bcl} 2$ protein was also analyzed by FCA. No difference was observed between the $\mathrm{Bcl} 2$ expression in the controls when compared to that in the cultures stimulated with M. leprae, PGL-I, AraLAM or ManLAM (Fig. 4A). A kinetic range to 25 to 40 cycles was performed on the Bax and Bak genes to verify the exponential phase of the both genes. The Bax and $B a k$ genes have low mRNA expression levels and were detected only after 30 cycles. Densitometry analysis of the bands in Fig. 4B showed a similar level of Bax and $B a k$ expression in comparison to the control when stimulated either by M. leprae or PGL-I.

\section{DISCUSSION}

The peculiar propensity of $M$. leprae to survive inside SC is one of the most intriguing events in infectious diseases and may account for the impossibility to address preventive or therapeutic measures to avoid nerve damage secondary to the infection. Difficulties in studying this subject arise from the inability to grow the bacillus in vitro (Truman 2005). This difficulty can be overcome by using an in vitro model of $\mathrm{SC}$ in the presence of $M$. leprae. A continuous cell line has the advantage of avoiding confounding effects due to cellular contaminants and the genetics of cell donors, which are common inconveniences in dissociated SC (Jessen \& Mirsky 2002). However, the best model to study SC function is the $\mathrm{SC} /$ axon co-culture, in which the effect of axon on $\mathrm{SC}$ can be assessed.

Dead M. leprae and its components can provide important information on how M. leprae affects SC biology (Rambukkana et al. 1997). However, nerve lesions occur in leprosy even in the absence of live bacilli, indicating that the dead bacilli and their components liberated into the nerve milieu perpetuate the nerve lesion (Rambukkana et al. 1997). It has recently been reported that PGLI was expressed in motor neurons of the spinal cord for more than ten years of 10 cured leprosy patients. M. leprae DNA has also been seen in SC (Aung et al. 2007).

The present study demonstrated that ST88-14 expresses many of the molecules predominantly present in non-myelinating SC (e.g., GFAP, NGF-R, CD44) and may be useful in mimicking $M$. leprae natural infection (Roh et al. 2006). Surprisingly, ST88-14 also expressed very low levels of MBP, suggesting that, although myelin was not produced, the gene was transcribed in this lineage. The expression of laminin also indicated a certain degree of SC maturation. However, the other components of the basal lamina did not appear to have been produced since no basal lamina could be identified. This observation confirmed previous data showing that ST88-14 expresses mRNA of $\alpha 1 \beta 1$ and $\gamma 1$ of laminin 2 and $\alpha$-dystroglycan molecules that mediate $M$. leprae adherence to SC (Rambukkana et al. 1997). Another integrin family member, ninjurin-1, was also constitutively expressed in SC. Analysis of these molecules in the nerve biopsies of leprosy patients showed upregulation in the neuritic lesions (Cardoso et al. 2007).

The most interesting data derived from the high expression of CD44 in this cell line. This is a membrane glycoprotein that, besides playing a key role in SC-neuron interaction, is also involved in organ development, neuronal axon guidance, numerous immune responses, and apoptosis modulation (Sherman et al. 2000). It is highly expressed in the neonatal nerve when SC proliferate. CD44 appears to mediate Erb2/Erb3 heterodimerization in response to neuregulin, an essential feature in SC differentiation (Ponta et al. 2003). However, low expression is seen in adults, and CD44 is primarily found in nonmyelinating SC (Yasuda et al. 2002). It has also been recently reported that $M$. leprae is able to activate Erb2 in SC via mechanisms other than those associated with neuregulin (Tapinos et al. 2006). It could, therefore, be speculated that the CD44 present in SC may be involved in the M. leprae/SC interaction.

The data indicating that M. leprae induced SC apoptosis corroborate previous reports (Oliveira et al. 2005). However, the induction of apoptosis in this cell line by PGL-I remains a controversial issue since previous studies failed to induce apoptosis in rat $\mathrm{SC}$ co-cultures challenged by PGL-I (Ng et al. 2000). In this study, however, PGL-I-coated polystyrene beads attached to and crossed 
the basal lamina/SC seen within non-myelinated SC. While inducing profound effects on SC, these beads did not induce apoptosis. In this system, the growth survival factor secreted by the neurons might be able to overcome the apoptotic effects induced by PGL-I, similar to the SC culture. It has been demonstrated, however, that apoptosis can be induced through p75 signaling after NGF binding (Soilu-Hänninen et al. 1999). Previous studies have demonstrated that $\mathrm{p} 75$-induced cell death constitutively (Rabizadeh et al. 1993). In this particular system, mechanisms involving apoptosis did not involve the Bcl2 family (Soilu-Hänninen et al. 1999).

In the present work, we showed that the mechanisms leading to apoptosis in ST88-14 either by M. leprae or PGL-I did not apparently include Bcl2 family members. The role of the extrinsic apoptosis pathway involving Fas/FasL is also under investigation, and our preliminary results suggest that this is not the pathway used by M. leprae. In previous reports, PGL-I was seen to inhibit human mononuclear blood cell proliferation in a concentration-dependent manner. This inhibition seems to be a general property of mycobacterium phenolic glicolipids working similarly to the growth modulating properties of gangliosides (Fournie et al. 1989). PGL-I exerts a nonspecific modulatory effect on the membranes of proliferating cells (i.e., Jurkat and Mott-4), perhaps analogous to the effect of gangliosides on growth and differentiation (Charlab et al. 2001).

The high variability observed in apoptosis rate with PGL-I administration could be explained by the difficulties encountered in obtaining a homogenous solution of these components as well as other stress conditions endured by SC cultures. Both TNF and NGF apoptosis induction is strongly influenced by cell density and stress conditions. Although none of these variables were analyzed in the present study, it cannot be ruled out that they must have affected the final results in some way (Boyle et al. 2005)

In conclusion, the data presented in this study suggested that the ST88-14 phenotype is close to non-myelinating SC, which would make it an excellent model for studying the $M$. leprae/SC interaction. It was also demonstrated that M. leprae and PGL-I induced low levels of apoptosis in cells by a mechanism not mediated by the activation of Bcl-2 family members.

\section{ACKNOWLEDGEMENTS}

To Roberta Olmo and Pedro Paulo de Abreu Manso for their technical assistance, and Judy Grevan for editing the text.

\section{REFERENCES}

Agrawal A, Pandit L, Dalal M, Shetty JP 2005. Neurological manifestations of Hansen's disease and their management. Clin Neurol Neurosurg 107: 445-454.

Aung T, Kitajima S, Nomoto M, En J, Yonezawa S, Arikawa I, Goto M 2007. Mycobacterium leprae in neurons of the medulla oblongata and spinal cord in leprosy. J Neuropathol Exp Neurol 66: 284-294.

Barry DP, Beaman BL 2006. Modulation of eukaryotic cell apoptosis by members of the bacterial order Actinomycetales. Apoptosis 11: 1695-1707.

Bhatheja K, Field J 2006. Schwann cells: origins and role in axonal maintenance and regeneration. Int J Biochem Cell Biol 38: 1995-1999.
Boyle K, Azari MF, Cheema SS, Petratos S 2005. TNFalpha mediates Schwann cell death by upregulating p75NTR expression without sustained activation of NFkappaB. Neurobiol Dis 20: 412-427.

Cardoso CC, Martinez AN, Guimarães PE, Mendes CT, Pacheco AG, de Oliveira RB, Teles RM, Illarramendi X, Sampaio EP, Sarno EN, Dias-Neto E, Moraes MO 2007. Ninjurin 1 asp110ala single nucleotide polymorphism is associated with protection in leprosy nerve damage. J Neuroimmunol 190: 131-138.

Castellino RC, De Bortoli M, Lin LL, Skapura DG, Rajan JA, Adesina AM, Perlaky L, Irwin MS, Kim JY 2007. Overexpressed TP73 induces apoptosis in medulloblastoma. BMC Cancer 7: 127.

Charlab R, Sarno EN, Chatterjee D, Pessolani MC 2001. Effect of unique Mycobacterium leprae phenolic glycolipid-I (PGL-I) on tumour necrosis factor production by human mononuclear cells. Lepr Rev 72: 63-69.

Corfas G, Velardez MO, Ko CP, Ratner N, Peles E 2004. Mechanisms and roles of axon-Schwann cell interactions. J Neurosci 20: $9250-9260$

Cruz WB 2006. Expressão do receptor para manose em células de Schwann e Schwnnoma ST88-14, PhD Thesis, Instituto Oswaldo Cruz, Rio de Janeiro, 83 pp.

Fournie JJ, Adams E, Mullins RJ, Basten A 1989. Inhibition of human lymphoproliferative responses by mycobacterial phenolic glycolipids. Infect Immun 57: 3653-3659.

Im JS, Tapinos N, Chae GT, Illarionov PA, Besra GS, DeVries GH, Modlin RL, Sieling PA, Rambukkana A, Porcelli SA 2006. Expression of CD1d molecules by human schwann cells and potential interactions with immunoregulatory invariant NK T cells. $J$ Immunol 15: 5226-5235.

Jessen KR, Mirsky R 2002. Signals that determine Schwann cell identity. J Anat 200: 367-376.

Marques MA, Antonio VL, Sarno EN, Brennan PJ, Pessolani MC 2001a. Binding of alpha2-laminins by pathogenic and non-pathogenic mycobacteria and adherence to Schwann cells. J Med Microbiol 50: 23-28.

Marques MA, Mahapatra S, Sarno EN, Santos S, Spencer JS, Brennan PJ, Pessolani MC 2001b. Further biochemical characterization of Mycobacterium leprae laminin-binding proteins. Braz J Med Biol Res 34: 463-470.

Mirsky R, Jessen KR 2007. Early events in Schwann cell development. In PJ Armati (ed), The Biology Schwann Cells, Cambridge University Press, Cambridge, p. 13-36.

Ng V, Zanazzi G, Timpl R, Talts JF, Salzer JL, Brennan PJ, Rambukkana A 2000. Role of the cell wall phenolic glycolipid-1 in the peripheral nerve predilection of Mycobacterium leprae. Cell 27: 511-524.

Oliveira RB, Ochoa MT, Sieling PA, Rea TH, Rambukkana A, Sarno E, Modlin RL 2003. Expression of Toll-like receptor 2 on human Schwann cells: a mechanism of nerve damage in leprosy. Infect Immun 71: 1427-1433.

Oliveira RB, Sampaio EP, Aarestrup F, Teles RM, Silva TP, Oliveira AL, Antas PR, Sarno EN 2005. Cytokines and Mycobacterium leprae induce apoptosis in human Schwann cells. J Neuropathol Exp Neurol 64: 882-890.

Ponta H, Sherman L, Herrlich PA 2003. CD44: from adhesion molecules to signaling regulators. Nat Rev Mol Cell Biol 4: 33-45.

Rabizadeh S, Oh J, Zhong LT, Yang J, Bitler CM, Butcher LL, Bredesen DE 1993. Induction of apoptosis by the low-affinity NGF receptor. Science 6: 345-348.

Rambukkana A, Salzer JL, Yurchenco PD, Tuomanen EI 1997. Neural targeting of Mycobacterium leprae mediated by the $\mathrm{G}$ domain of the laminin-alpha2 chain. Cell 21: 811-821. 
Roh J, Cho EA, Seong I, Limb JK, Lee S, Han SJ, Kim J 2006. Downregulation of Sox 10 with specific small interfering RNA promotes transdifferentiation of Schwannoma cells into myofibroblasts. Differentiation 74: 542-551.

Ryan JJ, Klein KA, Neuberger TJ, Leftwich JA, Westin EH, Kauma S, Fletcher JA, DeVries GH, Huff TF 1994. Role for the stem cell factor/KIT complex in Schwann cell neoplasia and mast cell proliferation associated with neurofibromatosis. J Neurosci Res 15: 415-432.

Sampaio EP, Moraes MO, Nery JA, Santos AR, Matos HC, Sarno EN 1998. Pentoxifylline decreases in vivo and in vitro tumour necrosis factor-alpha (TNF-alpha) production in lepromatous leprosy patients with erythema nodosum leprosum (ENL). Clin Exp Immunol 111: 300-308.

Sherman LS, Rizvi T A, Karyala S, Ratner N 2000. CD44 enhances neuregulin signaling by Schwann cells. J Cell Biol 150: 1071-1083.

Soilu-Hänninen M, Ekert P, Bucci T, Syroid D, Bartlett PF, Kilpatrick TJ 1999. Nerve growth factor signaling through $\mathrm{p} 75$ induces apoptosis in Schwann cells via a Bcl-2-independent pathway. $J$ Neurosci 15: 4828-4838.
Tapinos N, Ohnishi M, Rambukkana A 2006. ErbB2 receptor tyrosine kinase signaling mediates early demyelination induced by leprosy bacilli. Nat Med 12: 961-966.

Tapinos N, Rambukkana A 2005. Insights into regulation of human Schwann cell proliferation by Erk $1 / 2$ via a MEK-independent and p56Lck-dependent pathway from leprosy bacilli. Proc Natl Acad Sci U S A 102: 9188-9193.

Truman R 2005. Leprosy in wild armadillos. Lepr Rev 76: 198-208.

Vincent NG, Zanazzi G, Timpl R, Talts JF, Salzer JL, Brennan PJ, Rambukkanak A 2000. Role of the cell wall phenolic glycolipid-1 in the peripheral nerve predilection of Mycobacterium leprae. Cell 103: 511-524.

Yan N, Ricca C, Fletcher J, Glover T, Seizinger BR, Manne V 1995. Farnesyltransferase inhibitors block the neurofibromatosis type I (NF1) malignant phenotype. Cancer Res 15: 3569-3575.

Yasuda M, Nakano K, Yasumoto K, Tanaka Y 2002. CD 44: Functional relevance to inflammation and malignancy. Histol Histopathol 17: 945-950. 